\title{
Dynamic Analysis of the Mooring System for a Floating Offshore Wind Turbine Spar Platform
}

\author{
D. P. Zhang, K. Q. Zhu, B. Jing, R. Z. Yang, Z. C. Tang \\ Faculty of Maritime and Transportation \\ Ningbo University \\ Zhejiang Ningbo, China
}

\begin{abstract}
Based on the $5 \mathrm{MV}$ wind turbine of a certain renewable energy institute in America, the model of a floating offshore wind turbine spar platform mooring system has been established by Orcaflex. By calculating the load on the wind turbine, the hydrodynamic analysis of the wind turbine mooring system was researched and the mooring tension of the mooring system was analyzed in different load conditions. With the change of different fairlead position and different layouts of the fairleads, the optimization design of the mooring system has been given.
\end{abstract}

Keywords-wind turbine; spar platform; hydrodynamic analysis; mooring tension

\section{INTRODUCTION}

A satisfying mooring system for the offshore wind turbines is very complex. The almost constant wind, current and wave drift force would cause the natural position of the system to move and produce the impact load at the equilibrium position which would make the mooring chain appear tension-relaxation alternating motion. It would cause the mutation of the cable effective tension.

At present, the floating offshore wind turbine spar is only applied to the shallow water depth of 30m.[1-2] In this paper, based on the time domain coupled dynamic analysis method, the applicable water depth has reached up to $70 \mathrm{~m}$.

\section{MATHEMATICAL FORMULATION}

\section{A. The Description of the Wind Speed}

The change of the mean wind speed along the height generally conforms to the exponential law or logarithm law. Marine structures always uses American Petroleum Institute (API) spectrum. So Orcaflex modelling process also chose American Petroleum Institute (API) wind spectrum.

$$
\overline{\mathrm{u}}(z)=\left(\frac{z}{h}\right)^{1 / n} \bar{u}(h)
$$

Where $z$ is the height above sea level, $h$ is the reference height above sea level, generally taken to be $10 \mathrm{~m}, \bar{u}(z)$ is the mean wind speed at the height of $\mathrm{z}, \bar{u}(h)$ is the mean wind speed at the reference height. And $n$ is the wind profile index.

\section{B. Theory of the Motion of the Wind Turbine Blades}

The wind turbine blades are subjected to lift force $F_{W L}$, drag force $F_{W D}$ and a central moment $M$. All of these only depend on the incident angle $\alpha$. Therefore, Orcaflex used the lift coefficient $C_{W L}(\alpha)$, the drag coefficient $C_{W D}(\alpha)$ and the moment coefficient $C_{M}(\alpha)$.

$$
\begin{gathered}
F_{W L}=\frac{1}{2} C_{W L}(\alpha) \cdot \rho_{a} \cdot A \cdot V^{2} \\
F_{W D}=\frac{1}{2} C_{W D}(\alpha) \cdot \rho_{a} \cdot A \cdot V^{2} \\
M=\frac{1}{2} C_{M}(\alpha) \cdot \rho_{a} \cdot A \cdot V^{2} \cdot d
\end{gathered}
$$

$A$ is the blade area for the vertical wind direction, $V$ is the wind speed of the blade center, $d$ is the wind blade width, $\rho_{a}$ refers to the density of the air, here taken as $1.3 \mathrm{~kg} / \mathrm{m}^{3}$.

C. The Load Calculation of the Tower and the Selection of the Wave Theory

The tower can be viewed as a slender rod. In Orcaflex, it is calculated by the Morison formula. The acceleration of air in the calculation of wind load is small, so the inertia force term can be ignored.

$$
P(t)=0.5 \rho_{a} C_{D} v^{2}(t)
$$

$P(t)$ is the pressure variation with time ,also is the wind load on per unit length; $\rho_{a}$ is the density of air; is the drag coefficient $C_{D} ; v(t)$ is the wind speed.

Dean pointed out that in a variety of water depth, the Airy wave theory gives good results.[3] So we used the Airy wave theory in the modelling process .

\section{Calculation of Current Load and Wave Load}

The performance of the mooring line is equivalent to a nonlinear spring. The line is divided into a series of line segments which are then modelled by straight massless model segments with a node at each end. The model segments only model the axial and torsional properties of the line. The other properties are all lumped to the nodes.[4-8] 
That is also the foundation of mathematics model of line tension in Orcaflex.[9]

The tension FT of the spar platform is vector sum of 6 cables mooring forces of its mooring system. The spar platform is subjected to current load force FC, the drag force $\mathrm{FD}$, the inertia force FI, the buoyancy force FB, the gravity $\mathrm{FW}$, the wind loading force Fwind and moment Mwind which are delivered by the part above water, the water damping force FK, the water damping moment MK, the tension FT and the total moment MT that all the mooring chains give it. We assume the total force is $\mathrm{F}$ and the resultant moment is $\mathrm{M}$. The total external load can be expressed as;

$$
\begin{gathered}
F=F_{D}+F_{I}+F_{T}+F_{W}+F_{B}+F_{\text {wind }}+F_{K} \\
M=M_{\text {wind }}+M_{T}+M_{K}
\end{gathered}
$$

\section{Design OF THE MoORING System AND THE ModeL}

With 6 mooring chains anchoring the spar platform in the sea, two different layouts of the fairleads has been designed.

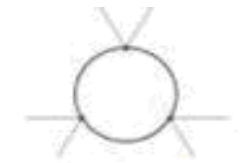

Grouping layout

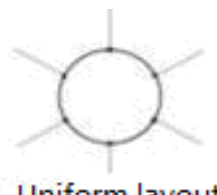

Uniform layout
FIGURE I. THE SCHEMATIC OF DIFFERENT LAYOUTS OF THE FAIRLEADS

\section{A. The Instruction of the Model Coordinate System}

Takes $\mathrm{W}$ as the origin point of the local coordinate system W-xyz, in which W represents the center of the wind turbine blades. To determine the coordinate axis G-XYZ, a global coordinate system has been made, in which $G$ represents the starting point of the global coordinate system, GX, GY, GZ, respectively represent $X$ axis $Y$ axis and $Z$ axis. The directions of wind, wave and current are relative to the global coordinate system of the GX axis and GY axis, just as shown in Figure 2- Figure 4.

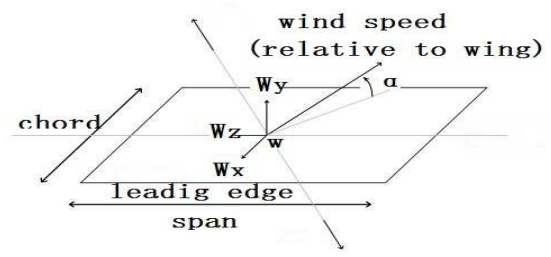

FIGURE II. LOCAL COORDINATE SYSTEM.

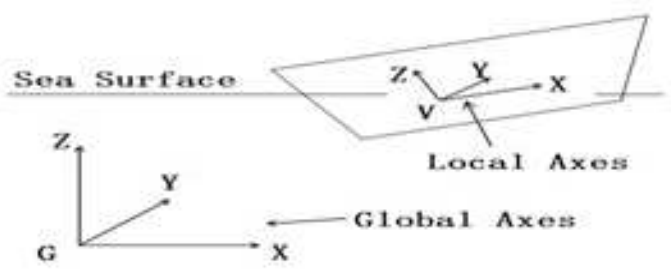

FIGURE III. GLOBAL COORDINATE SYSTEM.

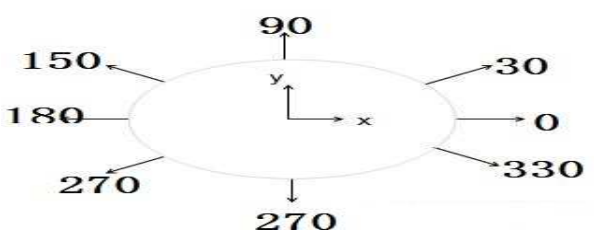

FIGURE IV. DIRECTION AND HEADINGS.

The angle $\alpha$ in the local coordinate in Figure 2 is the incident angle. The range of the incident angle is $-90 \mathrm{deg}$ to +90 deg.

\section{B. The Establishment of the Model in Orcaflex}

In this model, the main structure of the tower construction and underwater Spar column have been built by 6D buoy.

\begin{tabular}{|c|c|c|c|c|c|c|c|}
\hline \multirow[t]{2}{*}{$\operatorname{Mass}(t)$} & \multicolumn{3}{|c|}{$\begin{array}{c}\text { Mass moments of } \\
\left.\text { Inertia(t.m }{ }^{2}\right)\end{array}$} & \multirow{2}{*}{$\begin{array}{c}\text { Total } \\
\text { Length(m) }\end{array}$} & \multicolumn{3}{|c|}{$\begin{array}{l}\text { Centre of } \\
\operatorname{Mass}(m)\end{array}$} \\
\hline & $\mathrm{I}_{\mathrm{x}}\left(\mathrm{t} \cdot \mathrm{m}^{2}\right)$ & $\mathrm{I}_{\mathrm{y}}\left(\mathrm{t} \cdot \mathrm{m}^{2}\right)$ & $\mathrm{I}_{\mathrm{z}}\left(\mathrm{t} \cdot \mathrm{m}^{2}\right)$ & & $\mathrm{x}$ & $\mathrm{y}$ & $\mathrm{z}$ \\
\hline 50 & 100 & 100 & 800 & 121.1 & 0 & 0 & 100 \\
\hline
\end{tabular}

TABLE I. THE BASIC PARAMETERS OF THE MAIN STRUCTURE.

TABLE II. THE BASIC PARAMETERS OF THE TOWER AND SPAR.

\begin{tabular}{|c|c|c|c|c|}
\hline $\begin{array}{c}\text { Cylinder } \\
\text { segment }\end{array}$ & $\mathbf{I D}(\mathbf{m})$ & $\mathbf{O D}(\mathbf{m})$ & Length(m) & $\begin{array}{c}\text { Cumulative } \\
\text { Length(m) }\end{array}$ \\
\hline Tower & 2.75 & 2.78 & 80 & 80 \\
\hline $\begin{array}{c}\text { Transition } \\
\text { section 1 }\end{array}$ & 3.45 & 3.5 & 1 & 81 \\
\hline $\begin{array}{c}\text { Transition } \\
\text { section 2 }\end{array}$ & 4 & 4.5 & 1 & 82 \\
\hline Spar & 6 & 7 & 30 & 112 \\
\hline $\begin{array}{c}\text { Bottom } \\
\text { baffle }\end{array}$ & 0 & 6 & 0.1 & 112.1 \\
\hline
\end{tabular}

This main sea boundary condition for the system is as the following: the wave height , $\mathrm{H}=2 \mathrm{~m}$; the wave period, $\mathrm{T}=15 \mathrm{~s}$; the wave direction and current direction are both taken as 90 $\mathrm{deg}$, the current speed is taken as $3 \mathrm{~m} / \mathrm{s}$ in a certain sea state, the water depth is $70 \mathrm{~m}$. The inner diameter of each line is $0 \mathrm{~m}$, the outer diameter is $0.35 \mathrm{~m}$, the bending stiffness of them, $\mathrm{EI}=0$; the axial stiffness of them, $\mathrm{EA}=5200 \mathrm{KN}$; the line density is $0.15 \mathrm{t} / \mathrm{m}$, the Poisson's ratio $v$ is 0.5 , the length of each line is $60 \mathrm{~m}$. Completed in Orcaflex, the two models of different mooring systems have been shown in Figure 5.

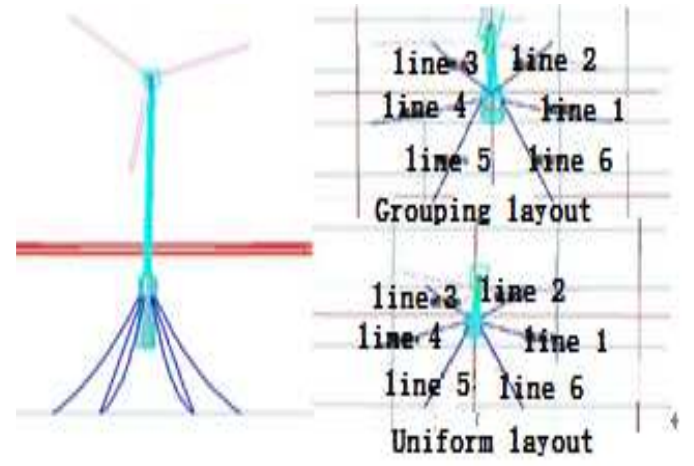

FIGURE V. THE MODELS OF TWO DIFFERENT MOORING SYSTEMS. 


\section{RESUlts}

According to the normal working conditions, wind direction is at $90 \mathrm{deg}$; when studying on the effect of different mooring form, the wind speed is taken as the working wind speed $15 \mathrm{~m} / \mathrm{s}$.

\section{A. The Dynamic Response of Grouping Layout}

Table 3 shows the maximum mooring tension of each mooring chain from large to small order: $6,5,3,2,4,1$. The mooring tension of line 1 and 4,line 2 and 3 , line 5 and 6 have respectively mutually symmetrical distribution, and the mooring tension of line 5 and line 6 is far larger than that of other chain line. The reason for this phenomenon is that the mooring arrangement of line 1 and line 4 , line 2 and line 3 , line 5 and line 6 are respectively mutually symmetrical; and line 5, 6 are in windward and upstream head sea direction, in order to prevent the wind turbine shift to the leeward direction, line 5,6 are under great mooring tension, that leads to asymmetric distribution of asymmetric mooring chain lines. Figure 6 illustrates, in the mooring system, the largest roll angle of the Spar platform is $9.27 \mathrm{deg}$, not more than the normal work angle (15 deg); in the mooring system, the maximum heave amplitude is less than $1.4 \mathrm{~m}$, which can satisfy the actual working requirement.

TABLE III. THE MOORING TENSION OF EACH CHAIN

\begin{tabular}{|l|c|c|c|}
\hline & Maximum(KN) & Minimum t(KN) & Mean(KN) \\
\hline line1 & 720.641 & 89.813 & 308.525 \\
\hline line2 & 1092.323 & 38.842 & 257.201 \\
\hline line3 & 1191.327 & 89.093 & 264.76 \\
\hline line4 & 857.417 & 105.911 & 370.560 \\
\hline line5 & 1446.966 & 42.054 & 911.873 \\
\hline line6 & 1457.586 & 128.248 & 1381.45 \\
\hline
\end{tabular}
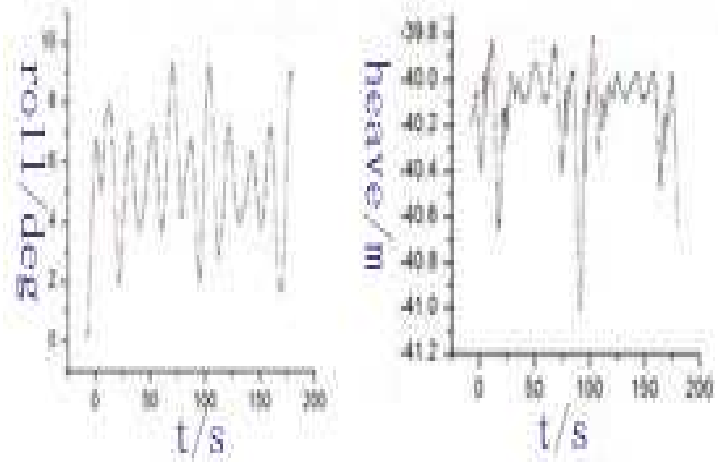

FIGURE VI. DYNAMIC RESULTS OF THE SPARPLATFORM.

\section{B. The Dynamic Response of Uniform Layout}

Table 4 shows the maximum mooring tension of each mooring chain from large to small order: 3, 5, 6, 2, 4, 1.The mooring tension of line 1 and line 4 have excellently symmetrical distribution. The mooring tension of line 2 and 3 , line 5 and 6 are respectively symmetrically distributed. In comparison Table 3 and Table 4, although the mooring tension maximum distribution has changed, but the mean mooring tension value of line 5 and line 6 are much larger than the others, which indicates the mooring tension of line 5 and line 6 are much larger than the others in most periods. With observation in Figure 7, the largest roll angle Spar platform is $6.42 \mathrm{deg}$, The maximum heave amplitude is less than $1 \mathrm{~m}$. Compared with the grouping layout, the uniform layout is safer.

TABLE IV. THE MOORING TENSION OF EACH CHAIN.

\begin{tabular}{|c|c|c|c|}
\hline & Maximum(KN) & Minimum t(KN) & Mean $(\mathbf{K N})$ \\
\hline line1 & 254.608 & 51.2 & 144.12 \\
\hline line2 & 1320.22 & 45.87 & 379.729 \\
\hline line3 & 1719.65 & 95.686 & 384.124 \\
\hline line4 & 295.981 & 65.616 & 146.677 \\
\hline line5 & 1498.858 & 63.849 & 1043.374 \\
\hline line6 & 1343.468 & 28.687 & 934.849 \\
\hline
\end{tabular}
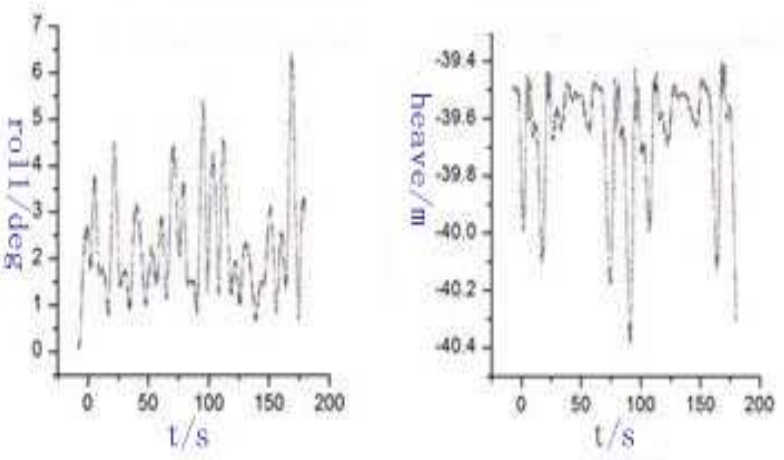

FIGURE VII. DYNAMIC RESULTS OF THE SPAR PLATFORM.

\section{CONCLUSIONS}

1) Under the same external load conditions, overall, the mooring tension of each mooring chain line in uniform layout is much larger than in grouping layout.

2) Under the same external load conditions, the uniform layout is better in the above two different layouts of the fairleads of the mooring system. And after moving the fairlead position properly, all the mooring chains increase the constraints of roll and heave of the wind turbine spar platform, while the grouping layout has fewer constraints on the spar platform.

\section{ACKNOWLEDGEMENTS}

Funding for this work was provided by the National Natural Science Foundation of China (Grant No. 11272160), the Science Program of Ningbo City (Grant No. szxl1066), and the Scientific Research Foundation of Ningbo University (Grant No. xk11339, XYL12014).

\section{REFERENCE}

[1] Hung Wei-ping, Liu Jian-jun, Zhao Zhan-hua. The state of the art study on offshore wind turbine structures and its development. The Ocean Engineering, 27 (2), pp. 130-134, 2009(in Chinese).

[2] Xia Yun-Qiang, Li Hua-jun, Tang Xiao-ning. Wind simuliation in physical model experiment of ocean engineering. Engineering Mechanics, 24 (1), pp. 28-33, 2008 (in Chinese).

[3] Dean R G, Perlin M. Intercomparision of Near-Bottom Kinematics by Several Wave Theories and Field and Laboratory Data. Coastal Engineering, 9(2), pp. 124-125, 1986.

[4] Zhu Ke-qiang, Cai Ying and Yu Chun-ling et al. Nonline Hydrodynamic Rssponse of Marine Cable-System Undergoing 
Random Dynamic Excitation. Journal of Hydrodynamics, 21(6), pp. 851-855, 2009.

[5] ZHU Ke-qiang et al,Dynamic Analysis On Ocean Cables System with Lumped Parameter Approach. Navigation of China, (3), pp. 10-12, 2007 (in Chinese).

[6] ZHU Ke-qiang, Li Dao-geng et al. Lumped-parameter analysis method for Time-domain of ocean cable-body systems. The Ocean Engineering, 20, (2), pp. 100-102, 2002 (in Chinese).

[7] ZHU Ke-qiang, et al. A Simulation of Nonlinear Coupling Dynamic Characteristic on a Deep-sea Tethered Remotely Operated Vehicle Multi-body System. The Ocean Engineering, 26(1), pp. 83-87, 2008 (in Chinese)

[8] ZHU Ke-qiang, MIAO Guo-ping, A multi-body space coupled motion simulation of hydrodynamics on a deep-sea tethered remotrly operated vehicle. Journal of Hydrodynamics,Ser.B. 20(2), pp. 210-215, 2008. ORCAFLEX Help File and User Manual, available from www.oricina.com. 